volume do fluido gastrico, na anemia perniciosa, enquanto a atividade anti-anemica por unidade de volume erá igual á normal. Além disto, não se deve esquecer que, de acôrdo com as pesquisas de Castle, a parte essencial de interação entre o fator intrinseco e o extrinseco. deve se dar no intestino delgado, e este, pois, pode ter influencia, ainda pouco conhec da, na patogenia da anemia perniciosa.

\title{
E. Mattar
}

The use of elecirocardiographic changes caused by induced anoxemy as a test for coronary insuficiency ( $O$ uso das alterações eletrocardiograficas causadas pela anoxemia como um test de insuficiência coronaria) - R. L. Levy, H. G. Bruenn, e N. G. Russell - Am. Journ. Med. Sc. vol. 197, n. ${ }^{\circ} 2$ (Fevereiro) 1939, pp. 241-247.

Utilizam os AA. um metodo para induzir anoxemia geral, empregando um aparelho que capacita o individuo a respirar uma mistura de $10 \%$ de oxigenio e $90 \%$ de nitrogenio, a uma amphtude normal de ventilação pulmonar. Estudam as alteraçōes da forma do ECG após a anoxemia, assim indu_ida, em 105 pessoas, sendo 66 normais, 23 com lesões das arterias coronarias, $11 \mathrm{com}$ suspeita de lesão coronaria, e 5 com severa anemia. As alterações eletrocardiograficas consideradas anormais foram: a) Desnivelamento de S-T além de $1 \mathrm{~mm}$. em qualquer derivação; b) Inversão parcial ou completa de $T$ na $1 .^{\text {a }}$ derivação, combinada com desnivelamento, mesmo minimo, de S-T; c) Completa inversão de $T$ na derivação 4; d) Inversão parcial de $T$ na 4. ${ }^{\text {à }}$ derivação, desde que combinada com desnivelamento, ainda minimo, em S-T. Estas alterações ocorreram em pacientes com sinais clinicos e sintomas de insuficiencia coronaria. Similares alterações foram observadas em anemicos, que não tinham sinais de lesão cardiaca. Não houve efeitos nocivos serios. No enianto, devido a reações desagradaveis, o test não deve ser realizado em pacientes com insuficiencia cardiaca, nem será repetido no mesmo paciente dentro de 24 hs. As alterações eletrocardiograficas causadas pela anoxemia provocała, podem ser utilisadas como um test clinico de insuficiencia da circulação coronaria, quer manifesta ou latente. Um index de "reserva coronaria" é assim obtido. Tambem será de valor, para distinguir dôres de origem coronaria das outras dôres torácicas, ou de dôres abdominais reflexas. E' possivel que o test possa ser empregado para o estudo do efelto de drogas, e de varios processos cirurgícos que modificam a circulação coronaria.

\section{E. Mattar}

Should digitalis be administered to patients with preexisting partial heart block? (Pode ser administrada digitalis a doentes com bloqueio parcial preexistente?) - H. L. Blumgart, e M. D. Altschule - Am. Journ. Med. Sc. v. 194, n. 4, (Outubro) 1939, pp. 455-463.

Ao tratar pacientes com bloqueio parcial preexistente, o medico é frequentemente colocado diante de uma dificil decisão, quanto a si digitalıs será prescrita, por causa do perigo da interferencia com a passagem dos impulsos, de um lado, e sobre as indicações claras de sua administração, de outro. 19 pacientes de 15 a 72 anos de :dade foram estudados. Insuficiencia cardiaca congestiva existia em quasi todos. Em 3, havia relações de $2: 1$ ou $1: 1$ entre as contrações auriculares e ventriculares. Em muitos, o prolongamento de P-R dependia de esclerose coronaria; em outros, havia cardiopatia reumatica. Foi utilisada uma preparação de digitalina estaridardizada, em doses um pouco menores que as de Eggleston, isto é, em doses que comumente são usadas. Os resultados demonstram que digitalina, em doses nocessarias para induzir efeitos terapeuticos, pode ser dada a pacientes com bloquero parcial, sem causar interferencia com a passagem dos impulsos das auriculas para os ventriculos. A exatidão da dose utilizada foi demonstrada pelos bons efeitos terapeuticos. Os 